US Army Corps

of Engineers ${ }_{\circledast}$

Engineer Research and

Development Center

\title{
The Behaviour of Near-Surface Soils Through Ultrasonic Near-Surface Inundation Testing
}

Oliver-Denzil S. Taylor, Amy L. Cunningham,

August 2021

Robert E. Walker, Mihan H. McKenna, Kathryn E. Martin,

and Pamela G. Kinnebrew 
The U.S. Army Engineer Research and Development Center (ERDC) solves the nation's toughest engineering and environmental challenges. ERDC develops innovative solutions in civil and military engineering, geospatial sciences, water resources, and environmental sciences for the Army, the Department of Defense, civilian agencies, and our nation's public good. Find out more at www.erdc.usace.army.mil.

To search for other technical reports published by ERDC, visit the ERDC online library at https://erdclibrary.on.worldcat.org/discovery. 


\section{The Behaviour of Near-Surface Soils Through Ultrasonic Near-Surface Inundation Testing}

Oliver-Denzil S. Taylor, Amy L. Cunningham, Robert E. Walker, Mihan H. McKenna, Kathryn E. Martin, and Pamela G. Kinnebrew

Geotechnical and Structures Laboratory

U.S. Army Engineer Research and Development Center

3909 Halls Ferry Road

Vicksburg, MS 39180

Final report

Approved for public release; distribution is unlimited.

Prepared for Assistant Secretary of the Army, Acquisition, Logistics and Technology

(ASAALT) Washington, DC 20314

Under Project Number 61102/T22/01 


\section{Preface}

This study was sponsored and funded through the Assistant Secretary of the Army, Acquisition, Logistics and Technology (ASAALT) under Project 61102/T22/01.

The work was performed by the U.S. Army Engineer Research and Development Center, Geotechnical and Structures Laboratory (ERDC-GSL). At the time of publication of this paper, the Deputy Director of ERDC-GSL was Mr. Charles W. Ertle II was Deputy Director of ERDC-GSL, and the Director was Mr. Bartley P. Durst.

This article was originally published online in Near Surface Geophysics on 24 April 2019.

The Commander of ERDC was COL Teresa A. Schlosser and the Director was Dr. David W. Pittman.

DISCLAIMER: The contents of this report are not to be used for advertising, publication, or promotional purposes. Citation of trade names does not constitute an official endorsement or approval of the use of such commercial products. All product names and trademarks cited are the property of their respective owners. The findings of this report are not to be construed as an official Department of the Army position unless so designated by other authorized documents. 


\title{
The behaviour of near-surface soils through ultrasonic near-surface inundation testing
}

\begin{abstract}
Seismometers installed within the upper metre of the subsurface can experience significant variability in signal propagation and attenuation properties of observed arrivals due to meteorological events. For example, during rain events, both the time and frequency representations of observed seismic waveforms can be significantly altered, complicating potential automatic signal processing efforts. Historically, a lack of laboratory equipment to explicitly investigate the effects of active inundation on seismic wave properties in the near surface prevented recreation of the observed phenomena in a controlled environment. Presented herein is a new flow chamber designed specifically for near-surface seismic wave/fluid flow interaction phenomenology research, the ultrasonic near-surface inundation testing device and new $v_{p}$-saturation and $v_{s}$-saturation relationships due to the effects of matric suction on the soil fabric.
\end{abstract}

\section{INTRODUCTION}

Seismic arrays are precisely located collections of seismometers utilized to monitor subsurface and near-surface events, spanning a variety of technologies from permanently emplaced borehole seismometer networks to monitor earthquakes (Chapman 2013), to mobile and temporarily deployed oil and gas land-streamer geophone survey rigs (Tsoflias et al. 2006). In each case, there is a trade-off between ideal location, such as quiet and isolated basement rock emplacement for global seismic earthquake monitoring, and ideal conditions, like those found in targeted near-surface seismic surveys that occur only at discrete points in time under non-variable meteorological conditions. Through careful analysis, these seismic arrays can forensically investigate events of interest, such as discrimination of nuclear and chemical explosions (Stump,
Pearson and Reinke 1999), pipeline explosions (Koper, Wallace and Aster 2003) and even military events (Bonner et al. 2013). Both ideal location and ideal condition seismic array techniques are able to effectively reconstruct source properties such as duration, spatial length, strength or dominant period and yield, because receiver side effects are able to be properly quantified for each deployment. This assessment critically relies on behavioural knowledge of the rock (deep borehole placement) or soil (shallow, temporary geophone deployments) through which the seismic energy will propagate. Unlike the traditional seismic array deployments discussed above, semi-permanent 'operational' seismic arrays deployed for extended periods of time are often situated within nearsurface soils, not hard rock or other more competent material, and are therefore subject to the meteorologically sensitive behaviour low-confinement soils can exhibit (Taylor et al. 2014).

Taylor et al. (2014) observed that near-surface postrain signals are amplified up to 14.7 -fold over the pre-rain 
signals in in situ sand testing, with significant shifts in spectral content and shear wave arrival times at low to negligible confining stresses. Moreover, Taylor et al. (2014) observed a significant shift in the shear wave velocities along all principle axes, wherein the soil fabric went from an anisotropic state to an isotropic state signifying a complex realignment of granular stresses. Fratta et al. (2005) illustrated the need for accurate new $v_{p}$-saturation and $v_{s}$-saturation relationships for validation of empirical and semi-empirical stiffness models used to derived elastic moduli. Therefore, understanding this relatively unconfined behaviour along with highly accurate elastic moduli becomes paramount in order to perform any detection, classification or localization of seismic sources over a broad spectrum of meteorological conditions.

Presented herein is a new flow chamber designed specifically for near surface seismic wave/fluid flow interaction phenomenology research, the ultrasonic near-surface inundation testing device and new $v_{p}$-saturation and $v_{s}$-saturation relationships due to the effects of matric suction on the soil fabric.

\section{THEORY}

\subsection{Near-surface soil behaviour}

The behaviour of dry, moist and saturated soils has been studied for over a century without adequately investigating the behaviour associated with transient saturation in upper the near surface, including the effects of rapid meteorological changes, dynamic fluid flow and variability of saturation on shallow seismic sensors. Though the inter-particle stresses in the top metre of the earth can have a significant effect on the shear modulus of the soil and consequently the wave velocities (Hassanizadeh, Celia and Dahle 2002; Lu and Sabatier 2009; Shen et al. 2016), the large variability in the pre- and post-rain waves, observed by Taylor et al. (2014), is not explained by simply accounting for microscopic inter-particle stresses at variable saturations (e.g. unsaturated soil mechanics as described by Bishop and Blight 1963; Lu, Godt and Wu 2010; Fredlund, Rahardjo and Fredlund 2012; and others), nor is it explained by accounting for seepage forces in Biot-Gassmann theory (Gassmann 1951; Biot 1956). For example, high-resolution shallow seismic reflection and refraction studies on tidal saturation infer changes in density from Biot-Gassmann theory wherein the shear modulus and the bulk modulus are assumed constant or nearly constant within the partially saturated range (Bachrach and Nur 1998a,b). Additionally in these studies, the measured volumetric water contents versus those derived from wave speeds show significant variability wherein the derived velocities are higher than those measured in situ (Bachrach and Nur 1998a,b). This observed wave speed variability can lead to classification and signal identification errors in shallow $(<1 \mathrm{~m}$ burial depth) semi-permanent 'operational' seismic arrays deployed for extended periods of time.

Many near-surface seismic velocity studies (e.g. Bachrach et al. 2000; Barriere et al. 2012) inundate the soil through groundwater table rise, which fails to replicate the dynamic inundation of the ground surface from a brief rain event, as observed by Taylor et al. (2014). Moreover, Taylor et al. $(2014,2019)$ show the potential for shear modulus and stressstrain behaviour variability as a function of gravimetric water content counter to the assumption of Biot-Gassmann theory, the refraction models assumptions by Bachrach and Nur (1998a,b), and other research wherein a single soil behaviour, e.g. poro-visco-elastic behaviour, or fixed value moduli are assumed (Bachrach, Dvorkin and Nur 2000; Barriere et al. 2012). The inclusion of suction for the determination of shear strength in unsaturated soil mechanics (e.g. Vanapalli et al. 1996; Lu et al. 2010; Han and Vanapalli 2016) do not accurately represent the changes in strength and matrix behaviour of sands under low confining pressures (Taylor et al. 2019). Therefore, the phenomenology observed by Taylor et al. (2014) must be a function of a physical behavioural process within the soil that is currently unaccounted for in prevailing theory (Taylor et al. 2019).

Recent research at the U.S. Army Engineer Research and Development Center has demonstrated that as confinement decreases, the soil does not act as a continuum; neither finite nor discrete element modelling can simulate the physical behaviour (Taylor et al. 2014; Song et al. 2017; Taylor et al. 2019). Moreover, current signal processing techniques do not account for soil fabric variability from wetting/drying hysteresis. Historically, the data used to produce the constitutive equations that found the basis of near-surface models are not representative of true low confinement regimes, in large part due to the dependency of these data on inferences from data collected with higher confinement laboratory testing equipment (Houston, Houston and Spadola 1988; Sture et al. 1998; Cho, Dodds and Santamarina 2006; Lu et al. 2010; Han and Vanapalli 2016; Taylor et al. 2019).

\subsection{Laboratory testing for low confinement soils}

Typical geotechnical laboratory testing equipment, for example triaxial, simple shear, resonant column, ring shear and soilwater retention curve devices, ultrasonic testing, etc., require 
some degree of confinement, for example latex membranes and seating loads, to maintain sample stability and systemsoil connectivity prior to testing. This requirement inevitably results in a condition that does not represent the upper $1 \mathrm{~m}$ of the subsurface profile, as no atmospheric elastic free-surface boundary exists within the experiment set-up. For example, a typical triaxial test will have a significant total stress confining pressure, $\sigma_{3}$, of approximately $100 \mathrm{kPa}$, and then an internal pore space pressure is then applied to create an effective stress condition of low confinement (e.g. $90 \mathrm{kPa}$ pore pressure can be applied to a specimen confined at $100 \mathrm{kPa}$ to achieve an effective stress condition of $10 \mathrm{kPa})$. Such pressures do not exist for natural surficial soils; therefore, the resulting laboratory data may not be representative of the actual granular matrix stress states (Cho and Santamarina 2001; Santamarina 2001; Taylor et al. 2014; Taylor et al. 2019). Recent research showed this to be the case through testing on unsupported columns of sand and low confinement resonant column testing (Taylor and Winters 2017; Taylor et al. 2019).

In addition to the testing apparatus, the method and repeatability of the sample preparation plays a significant factor in the potential range of acoustic propagation values and quantification of the initial and subsequent soil structure and behaviour (Oelze, O'Brien and Darmody 2002; Taylor et al. 2017).

\subsection{Field experimentation of near-surface soils}

Near-surface seismic research requires the generation of short, repeatable, broadband source signatures constant in spectral content such that variations in the received signal can be attributed solely to geophysical, geological and geotechnical phenomenology (Crane, Lorenzo and Harris 2013). However, field testing has been conducted using a variety of different sources at varying degrees of success (Jolly 1956; Miller et al. 1986, 1992; Hasbrouck 1991; Bachrach and Nur 1998a,b; Lu and Sabatier 2009; Yordkayhun et al. 2009; Crane et al. 2013; Bergamo et al. 2016a,b). Field testing is a valuable dataset especially for model validation and its use and importance should not be understated. However, in situ subsurface and soil particle heterogeneity is often generalized during data analysis. Testing results are thus site specific, which can make definitive statements about the cause of observational anomalies difficult without supporting laboratory data. In cases where experimentation is conducted on engineered soils under field conditions, for example Lu and Sabatier (2009), the repeatability of the soil preparation has influence on the experimental data as observed in more controlled laboratory environments (Taylor et al. 2017).

\section{MATERIALS AND METHODS}

\subsection{Ultrasonic near-surface inundation testing device}

To experimentally replicate and understand these effects in a controlled environment, a new laboratory testing apparatus -the ultrasonic near-surface inundation testing (UNIT) device - was designed specifically for the low confining stress, near-surface environment (Taylor and Martin 2017). The design criterion of the UNIT device is that it must replicate near-surface conditions while providing a reliable means to extract soil fabric behaviour under static and dynamic influxes of moisture. The influx of moisture must be representative of various quantities of rainfall and of small stresses such that particle reorientation does not occur in the case of static exchange of air/fluid volumes. An atmospheric, elastic, free-surface air/soil interface that allows for the development of uninhibited soil swell characteristics is essential for nearsurface investigations. Further, the shape, materials and size of the device must be sufficient to ensure that wave reflectance and the artificial transmission of the source signal around the outside of the cell chamber are effectively eliminated. All water used within the UNIT device must be initially purified, distilled and de-aired to remove the potential of chemical contaminants that could introduce an artificial bonding of soil particles.

The UNIT device, Fig. 1, is comprised of a soil cell, precipitation tank, reservoir tank and recirculating pump. The recirculating pump allows for a continuous controlled meteorological event that minimizes the surface impact of water droplets. For most geotechnical testing, water droplet impacts are negligible but for the small stress and strain conditions affecting granular re-orientation at the air/soil interface, not mitigating the surface impact can present an 'artefact' of the experimental setup and not actual phenomena. The top plate of the soil cell includes a pressure equalization port, which keeps the sample chamber at atmospheric pressure during testing. The UNIT, with a $15 \mathrm{~cm} \times 15 \mathrm{~cm} \times 15 \mathrm{~cm}$ interior dimension, has horizontal and vertical bender ports to measure seismic wave propagation perpendicular to, in-flow, and against the direction of fluid flow. The bender elements consist of a paired piezoelectric compressional ( $\mathrm{p}$-wave) and shear (s-wave) wave transducers that are $10-\mathrm{kHz}, 14$-volt sine wave drivers manufactured by GDS Instuments, Inc. London, United Kingdom. The bender elements can be arranged in 


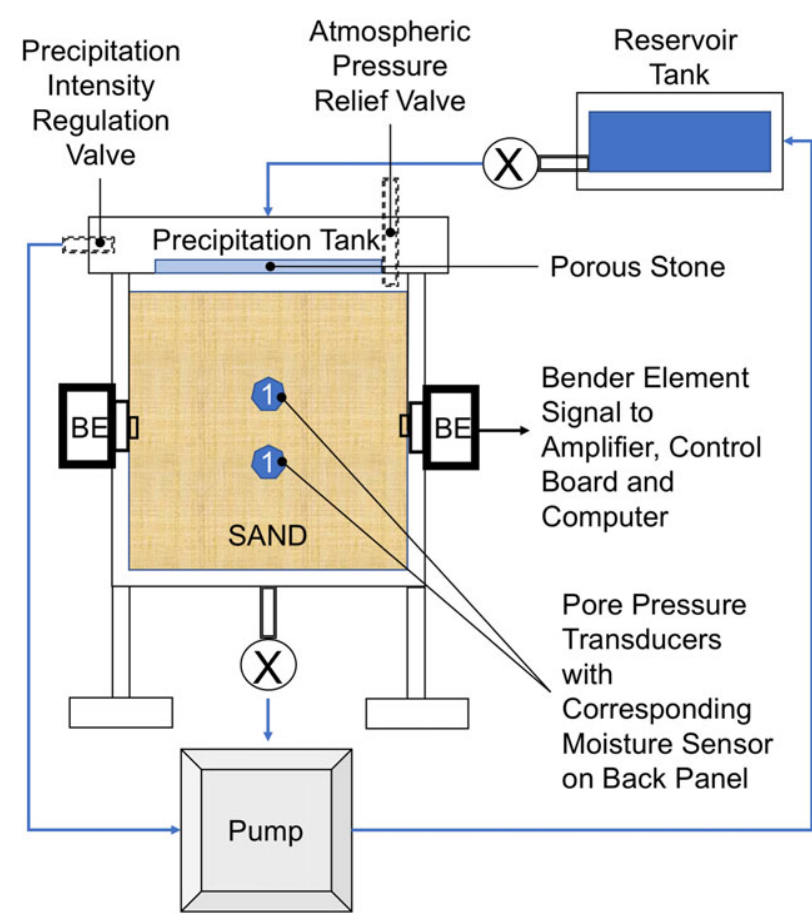

Figure 1 UNIT device schematic for this study. Bender elements are shown for radial motion comparison with field data (after Taylor and Martin 2017).

parallel or perpendicular orientation, depending on desired wave motion, Fig. 2. A series of resistivity posts or a moisture sensor is used to confirm the degree of saturation within the soil sample. Two piezometers are stacked vertically on the side of the sample chamber opposite moisture sensors to measure fluid pressures above and below the horizontal propagation pathway. Prior to the sample preparation, the outlet ball valve in the base plate is set to the desired drainage condition, ranging from free-draining to impermeable, and the head tank overflow outlet is set for a desired meteorological condition.

\subsection{Controlled sample preparation}

As sample preparation has a critical influence on the experimental limitations and data output, samples were prepared using an energy-based compaction method to ensure a repeatable initial soil fabric (Taylor et al. 2017). For laboratory reconstitution of a soil, there are three components that can be controlled; (a) the granular material, to include minerology, shape, particle distribution and mass; (b) the pore fluid, to include chemical composition, temperature and mass; and (c) the energy applied to the soil-water mixture, to include the method, quantity and uniformity of the application. The characteristics of the resulting specimen, for example void ratio, fabric, permeability, compressibility, behaviour, etc., are a by-product that can be readily reproduced between samples (Taylor et al. 2017). To reduce epistemic uncertainty from sample preparation, samples exceeding a $2 \%$ differential from targeted water content or volume were discarded.

For experimental validation, all samples were reconstituted, using the Taylor et al. (2017) protocol at a remoulding saturation of $24 \%$ using a compaction energy of $600 \mathrm{~kJ} / \mathrm{m}^{3}$, to a comparable soil fabric to the in situ field conditions observed by Taylor et al. (2014). The sand is a washed, poorly graded, medium-to-fine quartz-silica beach sand with $90 \%$ of the material between 0.25 and $0.85 \mathrm{~mm}$ in diameter, similar to the material within the region presented in Taylor et al. (2014). The coefficient of uniformity and coefficient of curvature of the grain-sized distribution are 1.52 and 1.12 , respectively. The specific gravity is 2.67 .

\subsection{Sample saturation for comparison to field conditions}

To replicate field conditions observed by Taylor et al. (2014) the drainage valve was set to a free-draining condition, that is the permeability at the sample base was greater than the permeability of the soil sample. The maximum saturation was achieved via a dynamic flow, that is a continuous rain event, until a steady-state condition was achieved wherein the inflow was equal to the outflow through the specimen. At the point of maximum saturation, no further absorption will occur. After a steady-state condition was achieved, the inflow of water was ceased and the specimen was allowed to freely drain through the sample base and evaporate through the atmospheric free-surface boundary interface. The drying process was accelerated with the aid of a small electric heater placed near the specimen. Care was taken so that the specimen was not subjected to direct exterior forces (e.g. vibrations and forced air), as artificial particle reorientation would render the subsequent data invalid. For the replication of field conditions, a single wetting/drying cycle was conducted over 3 months on a vibratory isolation table under controlled ambient conditions: $21^{\circ} \mathrm{C}$ at a relative humidity between $55 \%$ and $60 \%$.

\subsection{Controlled sample saturation for soil fabric studies}

To investigate the changes in the soil fabric or structure at discrete controlled saturation intervals, the drainage valve was set to an impervious condition, that is no flow was allowed through the specimen. Controlled saturation was achieved by 
(a)

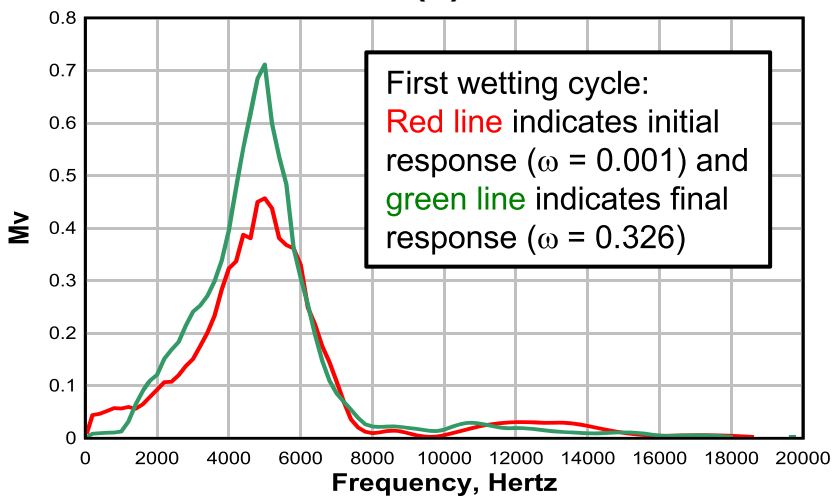

(c)

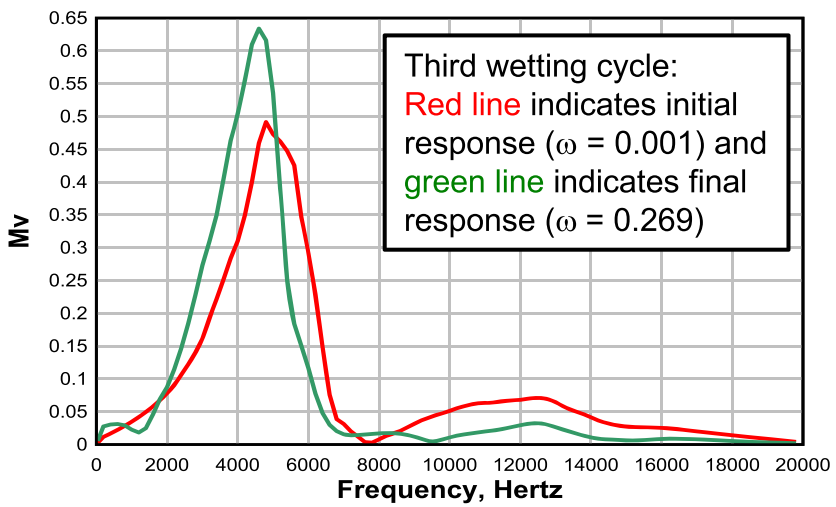

(b)

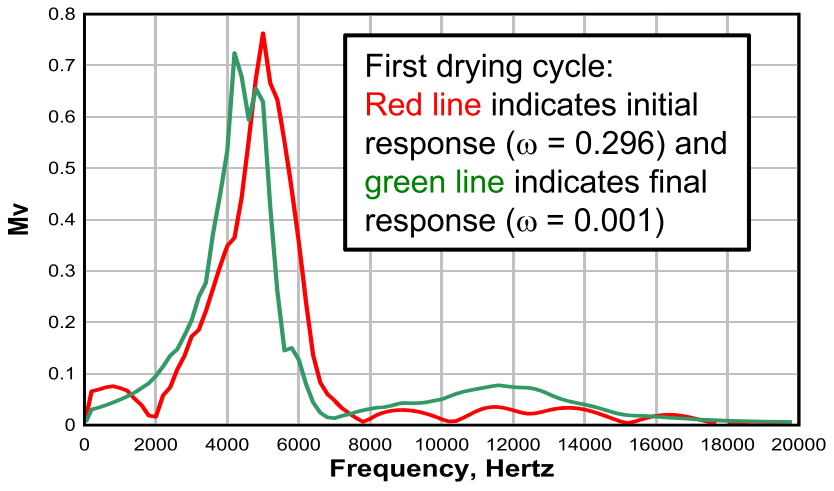

(d)

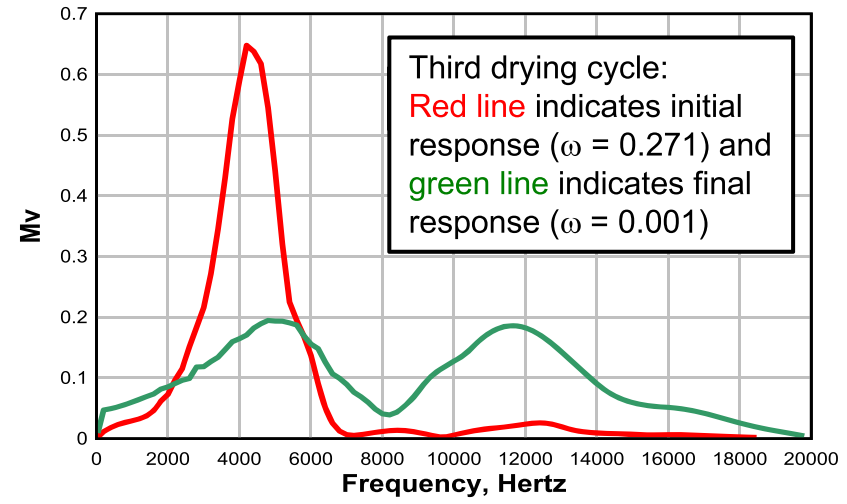

Figure 2 Horizontally propagating FFT response, measured in millivolts (mV), observed in Tip-to-Tip source function tests subjected to a 10-kHz, 0.1-ms, 14-volt sine wave driver. (a) First wetting cycle; (b) first drying cycle; (c) third wetting cycle; and (d) third drying cycle on the same specimen.

adding $70 \mathrm{~mL}$ of water, via a pipette, to the specimen over a 5 -minute period. The specimen was then covered with plastic wrap to prevent evaporation, and allowed to reach a hydraulic equilibrium, determined by no additional change in the pore pressure transducers. The amount of time required to reach hydraulic equilibrium is a function of the soil composition and the sample preparation. Four hours was required for this study. After hydraulic equilibrium was achieved, a measurement of compressional and shear waves, p- and s-waves, respectively, were taken for the known degree of saturation. This process was repeated until no further absorption of the water occurred and hydraulic equilibrium was maintained; this was determined to be the maximum saturation achievable by the soil without the use of applied external pressures that do not occur under field conditions. Once the specimen achieved maximum saturation, the specimen was allowed to dry while continuing to take moisture and wave speed measurements intermittently as the specimen dried. A single wetting/drying cy- cle was conducted over a 3-month timeframe under controlled ambient conditions: $21^{\circ} \mathrm{C}$ at a relative humidity between $55 \%$ and $60 \%$.

\subsection{Determination of an accurate source function with respect to saturation}

In order to numerically model wave behaviour within the ultrasonic near-surface inundation testing device, an accurate source function is required as the soil-bender element coupling is a function of the saturation within the soil fabric. The internal source function of a bender element is a pure sine wave; however, the peizoeletric element couples with the soil structure and is susceptible to saturation coupling effects. Therefore, tip-to-tip source testing was used as a baseline to determine how the bender element source input functioned during wetting and drying cycles. The bender elements were placed with the transmitter and the receiver parallel in the centre of 
the specimen at a spacing of less than $1 \mathrm{~mm}$. The tip-to-tip results over the initial wetting cycle (Fig. 2a, starting at an initial dry gravimetric water content, $\omega=0.001$, and wetted to a final gravimetric water content, $\omega=0.326$ ) indicate that the source function varies with saturation with a higher frequency amplitude response when saturated. The higher response amplitude was observed over all wetting and drying cycles, Fig. 2. A hysteretic effect was observed in the functional form of the produced source over multiple wetting/drying cycles. However, this hysteretic behaviour was not uniform over the number of cycles tested, for example the final drying response in the third drying cycle (green line in Fig. 2d) is functionally different than the final drying response of the first drying cycle (green line in Fig. 2b). Therefore, numerical model analyses require that the source function must be a measured laboratory value as a function of saturation and wetting/drying cycle and should not be simply assumed uniform.

\subsection{Direct measurement of wave speeds}

The use of piezoelectric bender elements has been used for decades in geotechnical laboratory testing (Shirley 1978; Bates 1989; Brignoli, Gotti and Stokoe 1996; Arulnathan, Boulanger and Riemer 1998; Pennington, Nash and Lings 2001; Lee and Santamarina 2005; Leong, Yeo and Rahardjo 2005; Viana da Fonseca, Ferreira and Fahey 2009; Gu, Yang and Huang 2013). The uncertainties within the data can be traced to the method of interpretation used to determine the wave travel time. Proper methods for picking wave arrivals using bender elements have been studied extensively for several decades (e.g. Arulnathan et al. 1998; Lee and Santamarina 2005; Leong et al. 2005; Viana da Fonseca et al. 2009). The shear wave arrival was determined through cross-correlation (Viana da Fonseca et al. 2009) and manual inspection to determine the correct travel time. The p-wave was excluded from the cross-correlation by identifying the end of the $\mathrm{p}$ wave in the time-series and performing the cross-correlation on the signal only after that time. During inundation, the results indicated a decrease in s-wave amplitude wherein the cross-correlation method did not work even when an s-wave could be visually identified, which was indicative of significant changes to wave energy and spectral phase content. Therefore, the two methods must be used in conjunction to determine the correct wave arrival and interpret the change in spectral content as observed in Taylor et al. (2014).

The ratio of the transmitted signal wavelength to the bender element's length $\left(\lambda / l_{b}\right)$ greatly affected accuracy of the travel time for a given sample as well as the signal-to-noise ratio (SNR) defined as (Carlson 1986; Arulnathan et al. 1998; Leong et al. 2005; Viana da Fonseca et al. 2009):

$\mathrm{SNR}=10 \log \frac{\text { Signal power }}{\text { Noise power }}$,

where the noise and signal power can be obtained from the power or frequency spectrum of the receiver signal. An SNR of at least $4 \mathrm{~dB}$ is required for wave speed measurements (Leong et al. 2005). The transmission frequency of $10 \mathrm{kHz}$ was chosen to maximize the travel time accuracy while reducing near-field effects (Leong et al. 2005). The wave path length to wavelength ratio must be a minimum of 3.33 per Leong et al. (2005); for this study, the minimum wave path to wavelength ratio is 3.40 for the fastest p-wave velocity. A minimum of 50 stacked waveforms were used at each data interval to determine the propagated signal. Propagation testing within the ultrasonic near-surface inundation testing device can investigate wave propagation horizontally and vertically (both with and against fluid flow). The orientation of the bender elements was dependent on the desired motion to be investigated; parallel elements for radial motion and perpendicular for translational motion. To minimize the noise associated with dynamic fluid flow and investigate soil fabric effects, the horizontal radial motion bender element orientation is presented herein.

\section{RESULTS}

\subsection{Soil fabric effects: compressional wave velocity}

The shear wave response correlates to the soil structure or fabric and is of principle interest for geotechnical engineering and soil behavioural characteristics. However, within the near surface, the p-wave and s-wave response are equally critical for research with respect to detection, classification and localization signal processing schemes. The p-wave velocity, $v_{p}$, of the soil is usually treated as effective solid continuum and expressed as

$v_{p}=\sqrt{\frac{\mathrm{K}+\frac{4}{3} G}{\rho}}$,

where $\mathrm{K}$ is the bulk modulus, $G$ is the shear modulus and $\rho$ is the bulk density. However, $\mathrm{K}$ and $G$ are functionally dependent on the degree of saturation, the fabric or structure of the soil, and require a priori knowledge of the saturation impacts on the granular contacts and stiffness matrix (Cho and Santamarina 2001; Fratta et al. 2005; Taylor et al. 2014). The characteristic soil behaviour, outside of the residual and saturated regions, is assumed to be governed by the soil's 


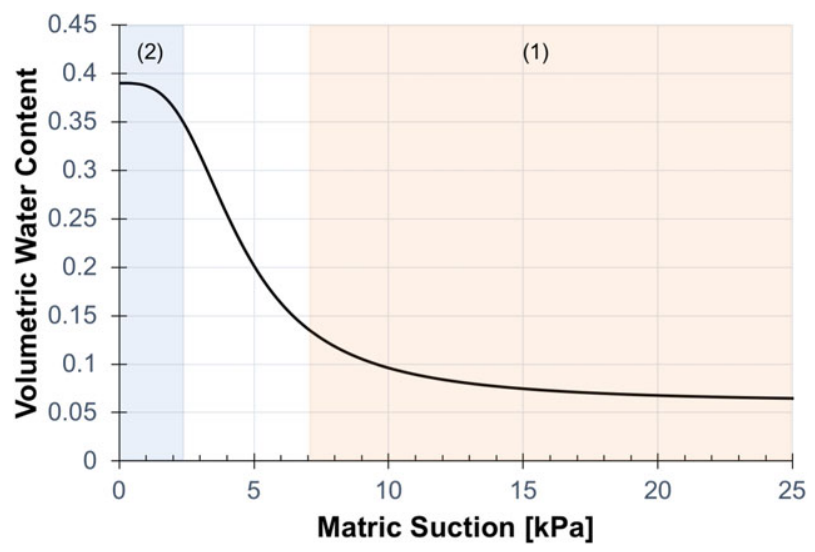

Figure 3 Soil-water retention curve after Walshire et al. (2017). (1) The residual region; (2) saturated region. matric suction defined by the soil-water characteristic curve (SWCC), soil-water retention curve (SWRC), or more broadly the suction-water content relationship (SWR) (Fredlund 2002; Fratta et al. 2005; Lu and Likos 2006; Lu and Sabatier 2009; Lu et al. 2010; Fredlund et al. 2012; Malaya and Sreedeep 2012; Han and Vanapalli 2016; Muraleetharan, Hoyos and Ge 2016). Therefore, it is assumed that the $v_{p}$ response should follow a similar trend, that is functional expression, to that of the soil matric suction. Walshire et al. (2017) performed a detailed laboratory investigation on the matric suction potential of this material with the data fit using the van Genuchten (1980) numerical model, expressed as

$\theta=\theta_{r}+\frac{\left(\theta_{s}-\theta_{r}\right)}{\left[1+(\alpha \psi)^{n}\right]^{1 / 1-n}}$,

Table 1 UNIT $v_{p}$-saturation and $v_{s}$-saturation data from controlled sample saturation

\begin{tabular}{|c|c|c|c|c|}
\hline & Original Identifier & Gravimetric Saturation & P-Wave Velocity $(\mathrm{m} / \mathrm{s})$ & S-Wave Velocity $(\mathrm{m} / \mathrm{s})$ \\
\hline \multirow[t]{11}{*}{ First static infiltration cycle } & Cube2_stat_70ml_3_P-wave & 0.09 & 269 & 131 \\
\hline & Cube2_stat_140ml_3_P-wave & 0.10 & 287 & 134 \\
\hline & Cube2_stat_210ml_3_P-wave & 0.16 & 282 & 127 \\
\hline & Cube2_stat_280ml_3_P-wave & 0.21 & 326 & 127 \\
\hline & Cube2_stat_350ml_3_P-wave & 0.27 & 368 & 113 \\
\hline & Cube2_stat_420ml_3_P-wave & 0.31 & 378 & 111 \\
\hline & Cube2_stat_560ml_3_P-wave & 0.42 & 385 & 110 \\
\hline & Cube2_stat_630ml_3_P-wave & 0.53 & 413 & 110 \\
\hline & Cube2_stat_700ml_3_P-wave & 0.62 & 411 & 110 \\
\hline & Cube2_stat_770ml_3_P-wave & 0.69 & 425 & 107 \\
\hline & Cube2_stat_838ml_3_P-wave & 0.70 & 426 & 104 \\
\hline \multirow[t]{10}{*}{ First static drying cycle } & Cube2_stat_4-4-18_P-wave & 0.65 & 421 & 109 \\
\hline & Cube2_stat_4-5-18_P-wave & 0.52 & 413 & 111 \\
\hline & Cube2_stat_4-6-18_P-wave & 0.36 & 382 & 113 \\
\hline & Cube2_stat_4-10-18_P-wave & 0.25 & 349 & 119 \\
\hline & Cube2_stat_4-12-18_P-wave & 0.18 & 285 & 119 \\
\hline & Cube2_stat_4-13-18_P-wave & 0.17 & 285 & 126 \\
\hline & Cube2_stat_4-18-18_P-wave & 0.16 & 286 & 128 \\
\hline & Cube2_stat_4-20-18_P-wave & 0.13 & 261 & 136 \\
\hline & Cube2_stat_4-24-18_P-wave & 0.12 & 260 & 139 \\
\hline & Cube2_stat_4-26-18_P-wave & 0.07 & 260 & 139 \\
\hline \multirow[t]{12}{*}{ Second static infiltration cycle } & Cube2_stat_70ml_4_P-wave & 0.08 & 262 & 134 \\
\hline & Cube2_stat_140ml_4_P-wave & 0.24 & 289 & 118 \\
\hline & Cube2_stat_210ml_4_P-wave & 0.28 & 353 & 112 \\
\hline & Cube2_stat_280ml_4_P-wave & 0.30 & 362 & 118 \\
\hline & Cube2_stat_350ml_4_P-wave & 0.32 & 389 & 118 \\
\hline & Cube2_stat_420ml_4_P-wave & 0.34 & 408 & 116 \\
\hline & Cube2_stat_490ml_4_P-wave & 0.38 & 421 & 114 \\
\hline & Cube2_stat_560ml_4_P-wave & 0.43 & 423 & 111 \\
\hline & Cube2_stat_630ml_4_P-wave & 0.55 & 433 & 105 \\
\hline & Cube2_stat_700ml_3_P-wave & 0.66 & 425 & 114 \\
\hline & Cube2_stat_770ml_3_P-wave & 0.69 & 425 & 100 \\
\hline & Cube2_stat_827.2ml_3_P-wave & 0.70 & 420 & 108 \\
\hline
\end{tabular}




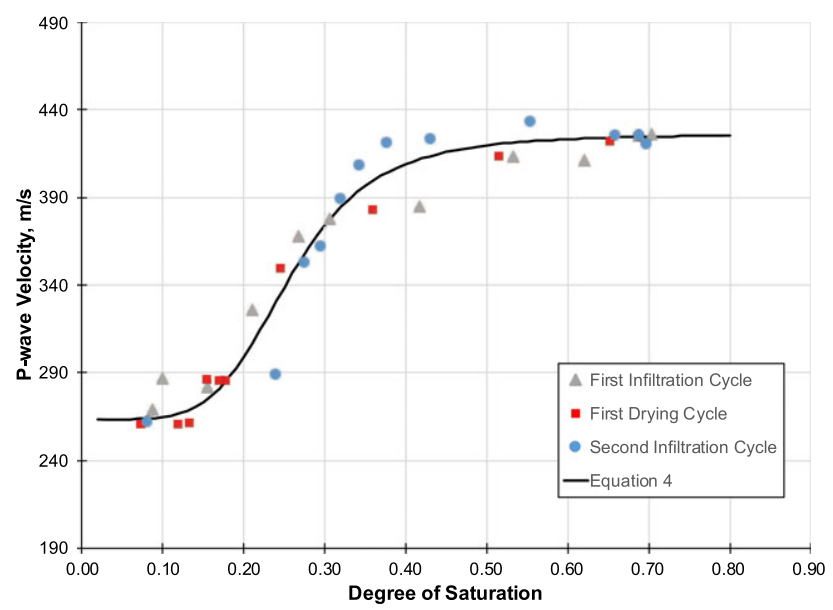

Figure 4 Relationship of p-wave velocity to saturation from controlled sample saturation.

where $\theta, \theta_{r}$ and $\theta_{s}$ are the volumetric water content, the residual volumetric water content $(0.06)$ and saturated water content (0.39), respectively. Note that $\alpha$ (in units of $1 /$ pressure; 0.26 in this study) and $n$ are curve-fitting parameters related to the pore size distribution (3.29 in this study), and $\psi$ is the matric suction. The SWRC for this material is shown in Fig. 3, from Taylor et al. (2019).

The ultrasonic near-surface inundation testing (UNIT) $v_{p}$ data, Table 1 and Fig. 4, follows the same functional relationship to equation (3) and Fig. 3, where the $v_{p}$ is unchanged within the residual (dry) and saturated regions. Thus, the relationship between $v_{p}$ and the degree of saturation, $S$, was fit

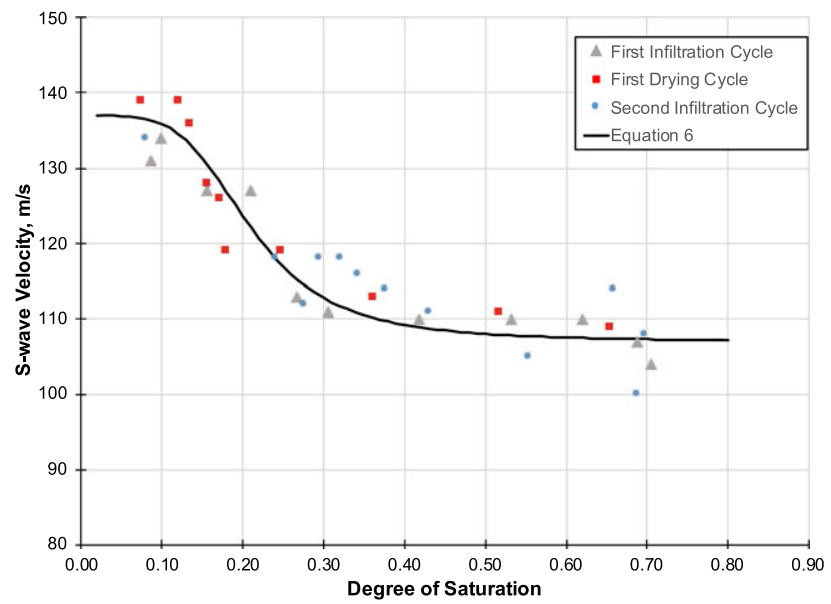

Figure 5 Relationship of s-wave velocity to saturation from controlled sample saturation. numerically based on a modified form of the van Genuchten (1980) matric suction relationship as

$v_{p}=v_{p}^{s}+\frac{v_{p}^{r}-v_{p}^{s}}{\left[1+(\alpha S)^{n}\right]^{(m)}}$,

where $v_{p}^{s}$ is the p-wave velocity corresponding to the saturated state (i.e. $426 \mathrm{~m} / \mathrm{s}$ for degree of saturation greater than $70 \%$ ), $v_{p}^{r}$ is the p-wave velocity corresponding to the residual condition where a soil's matric suction does not contribute to the behaviour of the soil element (i.e. $264 \mathrm{~m} / \mathrm{s}$ that corresponds to residual saturation $(S<13 \%)$ for this soil) and $\alpha, m$ and $n$ are empirical curve fitting parameters (i.e. 4.0, 0.9 and 5.15, respectively, in this study). Unlike semi-theoretical models (e.g. Fratta et al. 2005), equation (4) implicitly accounts for all microscopic (i.e. granular level) variability in actual moduli behaviour with saturation.

Both field and laboratory investigations indicate the potential for correlation of $v_{p}$ to the degree of saturation (Tsukamoto et al. 2002; Yang 2002; Takahashi et al. 2006). However, other research has shown that using the $v_{p}$ to determine fully saturated conditions is not reliable (Ishihara, Huang and Tsuchiya 1998; Tamura et al. 2002; Naesgaard, Byrne and Wijewckreme 2007). The results of the UNIT testing illustrate that while a $v_{p}$-saturation relationship, equation (4), does exist, the material exhibits a sharp increase in $v_{p}$ with the degree of saturation between $20 \%$ and $40 \%$ with little change outside this range, irrespective of wetting or drying cycles, Fig. 4. Therefore, using $v_{p}$ as an indicator for the degree of saturation is only accurate within the $20-40 \%$ saturation region and should not be used to determine if a soil is in a fully saturated condition.

\subsection{Soil fabric effects: shear wave velocity}

Small strain properties of soil, that is shear modulus, Young's modulus, bulk modulus, constrained modulus and Poisson's ratio, are critical in understanding and modelling many geotechnical and geophysical problems (Fratta et al. 2005; Barriere et al. 2012). The shear wave velocity, $v_{s}$, is typically used as a measure of the soil structure or fabric and typically defines the shear modulus, $G$, as

$G=\left[\bar{p}+\frac{p^{*} p_{A}}{p^{*}+p_{A}}\right] v_{s}^{2}$,

where $\bar{\phi}$ is the mass density of the elastic media, $p^{*}$ is the mass density of the fluid, and $p_{A}$ is the mass density of the additional mass in relation to the fluid-structure coupling. For a saturated soil, the total density can be substituted in the 

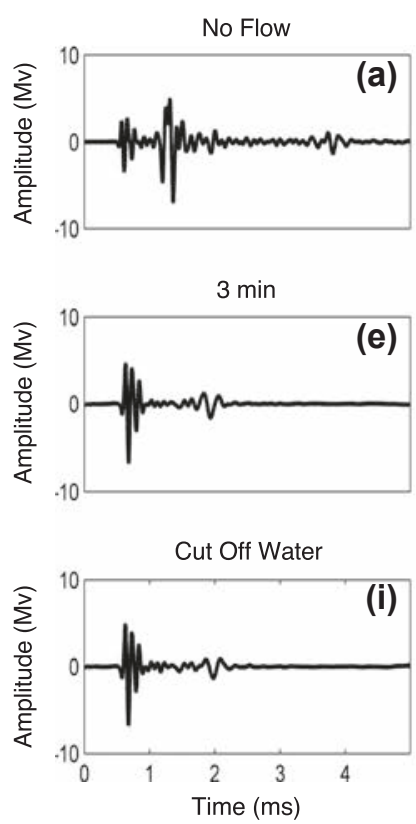

Begin Flow

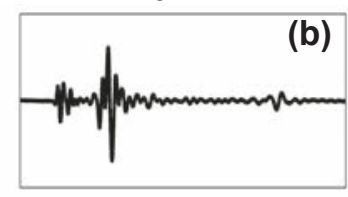

$4 \min$

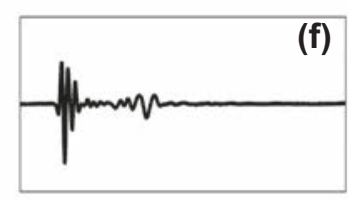

Draining

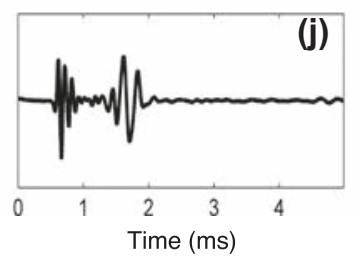

$1 \mathrm{~min}$

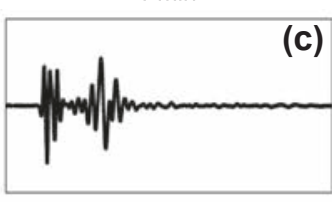

7 min

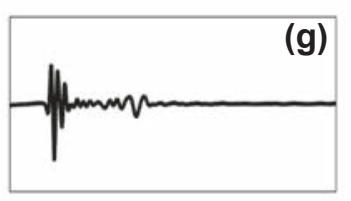

Draining

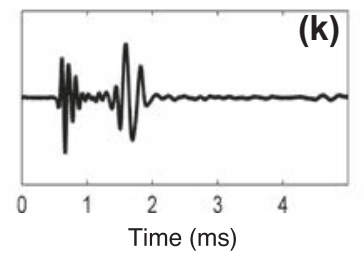

$2 \min$

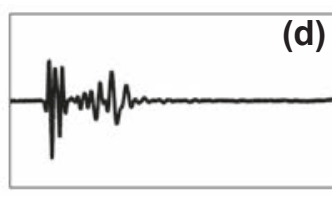

$20 \mathrm{~min}$

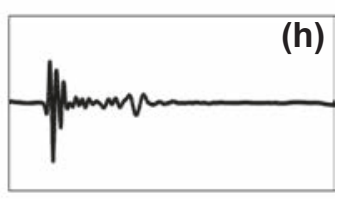

Draining

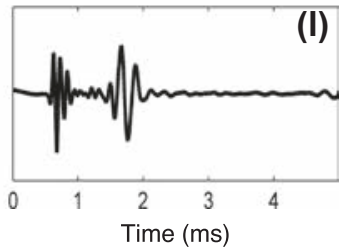

Figure 6 Horizontally propagating time-history for a single dynamic wetting/drying cycle. Panels A-D and J-L have an identifiable s-wave. Panels E-I do not have identifiable s-waves.

denominator as a first-order approximation of the shear wave velocity but $p_{A}$ varies with both permeability and grain size.

The ultrasonic near-surface inundation testing $v_{s}$ data, Table 1 and Fig. 5, follows the same functional relationship to equation (4) and Fig. 3, where the $v_{s}$ is unchanged within the residual (dry) and saturated regions. As $v_{s}$ is typically used as a measure of soil fabric stiffness, it has the same dependency as $v_{p}$ with matric suction thus, the relationship between $v_{s}$ and the degree of saturation, $S$, was fit numerically as

$v_{s}=v_{s}^{s}+\frac{v_{s}^{r}-v_{s}^{s}}{\left[1+(\alpha S)^{n}\right]^{(m)}}$,

where $v_{s}^{s}$ is the shear wave velocity corresponding to the saturated state (i.e. $107 \mathrm{~m} / \mathrm{s}$ for degree of saturation greater than $70 \%), v_{s}^{r}$ is the shear wave velocity corresponding to the residual condition where a soil's matric suction does not contribute to the behaviour of the soil element (i.e. $137 \mathrm{~m} / \mathrm{s}$ that corresponds to residual saturation $(S<13 \%$ ) for this soil) and $\alpha$, $m$ and $n$ are empirical curve fitting parameters (i.e. 5.1, 0.8 and 4.5 , respectively, in this study).

Unlike Fig. 4, the variation in shear wave magnitude with degree of saturation is significantly smaller with the $v_{s}$ decreasing with increasing saturation. During dynamic flow, that is simulated rain events, it was observed that $v_{s}$ amplitude decreased to less than the signal noise and was therefore undetectable when the specimen achieved a steady state flow condition, the point of maximum degree of saturation (72-
$79 \%$ ), Fig. 6. This observed response is in keeping with field observations by Taylor et al. (2014). Once the influx of water ceased and the degree of saturation decreased to below $72 \%$ the $v_{s}$ could be identified, Fig. 6 . The combination of a damped $v_{s}$ amplitude and a maximum degree of saturation of $72-79 \%$ suggests that during the wetting process the soil passes through the suction failure plane, that is the matric suction is insufficient to provide enough tensile strength to maintain a continuum within the grains without an increase in external confinement. Thus, the specimen should no longer be represented as a continuum, but rather as failed mass or viscoelastic material. This conclusion is further supported by self-supporting unconfined drained triaxial testing presented by Taylor et al. (2019), wherein suction failure is observed between $70.5 \%$ and $76.5 \%$ saturation with the specimen behaving as a viscoelastic media during failure.

\subsection{General waveform observations}

A modified, discrete Fast Fourier Transform (FFT) is utilized to investigate the wetting and drying cycles in frequency space of the detrended data (Smart and Flinn 1971; Swarztrauber 1982; Press et al. 1986). The discrete modified FFT is used specifically to incorporate the entire time history without having to pad, filter or apply a window to the data before transforming the time domain into the frequency domain 
(a)

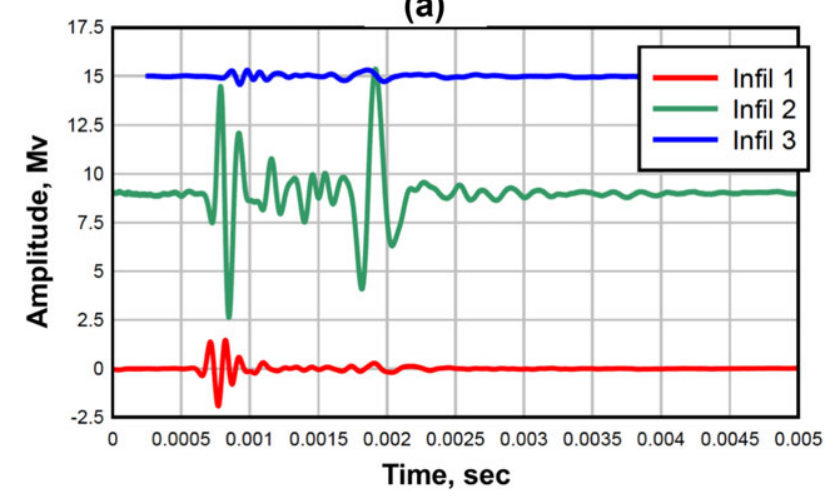

(b)

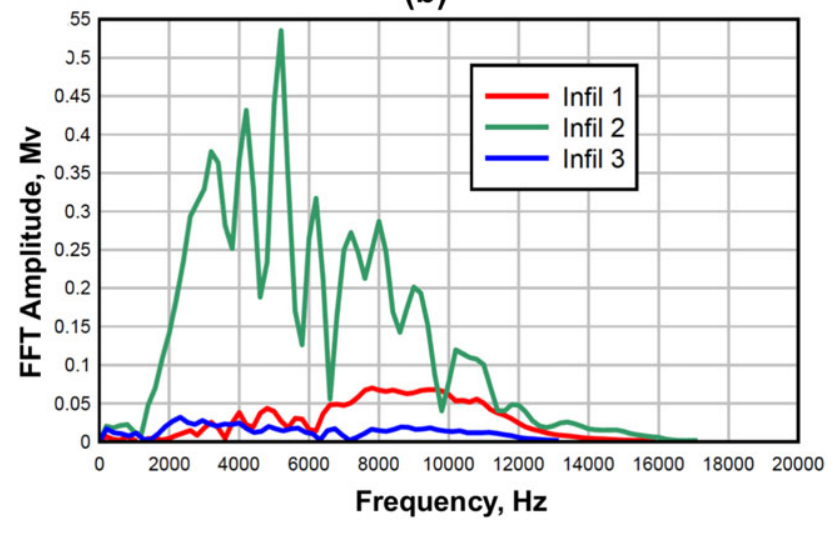

Figure 7 Horizontally propagating time histories and FFT response for three wetting cycles on the same specimen. The wetting cycle starts at a residual (dry) moisture content and is then saturated until no additional fluid is absorbed by the soil fabric. The data are the final saturation condition for each wetting cycle.

(Swarztrauber 1982). The FFT response and time histories of the propagated source, Figs 7 and 8, indicate an untrended variability for both wetting and drying cycles, respectively. The time histories, Figs 7 (a) and $8(a)$, suggest that the shear wave can arrive sooner or later than the previous cycle state, implying that the soil fabric is not static, despite there not being any measurable volumetric changes during testing. In the FFT space, similar characteristic changes can be observed both in tip-to-tip source testing, Fig. 2, and in propagation testing, Figs $7(\mathrm{~b})$ and $8(\mathrm{~b})$; however, these similarities are not observed at the same number of wetting and drying cycles. For example, the double peak FFT response, Fig. 2(d), is observed in the third drying cycle in tip-to-tip testing but in the fourth drying cycle in the propagation testing, Fig. 8(b). This change in wave characteristics suggests a stochastic change in fabric structure after each cycle; thus, the assumption of constant or discrete values of moduli, porosity, Poisson's ratio and associated density are not universally valid for all satu-

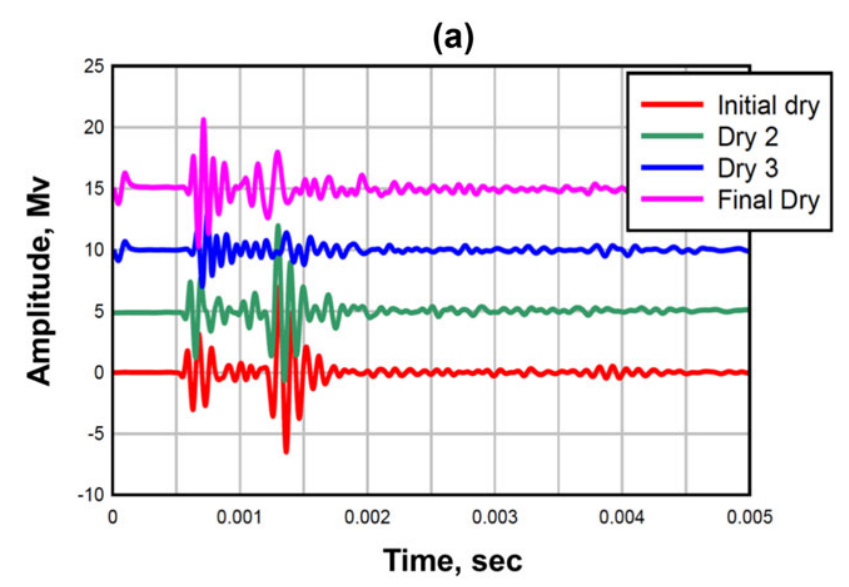

(b)

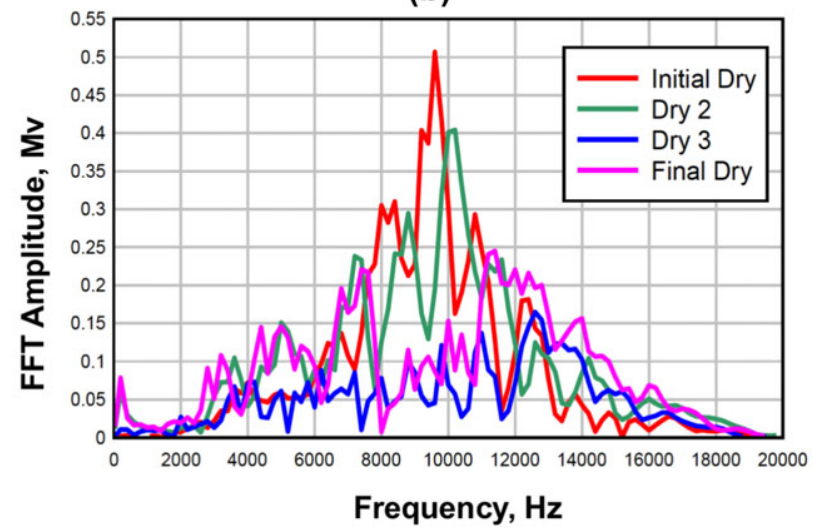

Figure 8 Horizontally propagating time histories and FFT response for four drying cycles on the same specimen as Fig. 7. The drying cycle begins at the saturated state and dried until a residual (dry) moisture content is measured. The data are the residual (dry) state for each drying cycle.

ration conditions. Rather, each discrete degree of saturation will have a distribution of wave characteristics, moduli and wave speeds and the behaviour at any such discrete interval should be obtained via a probabilistic numerical simulation. These distributions are beyond the scope of this paper and the subject of ongoing research.

Table 2 Comparison of Taylor et al.(2014) field data and UNIT $v_{p}$ and $v_{s}$ measurements

\begin{tabular}{|c|c|c|c|c|}
\hline & \multicolumn{2}{|c|}{ Taylor et al. (2014) } & \multicolumn{2}{|l|}{ UNIT Data } \\
\hline & pre-rain & post-rain & residual saturation & $25 \%$ saturation \\
\hline$v_{p}$ & $284 \mathrm{~m} / \mathrm{s}$ & $333 \mathrm{~m} / \mathrm{s}$ & $280 \mathrm{~m} / \mathrm{s}$ & $339 \mathrm{~m} / \mathrm{s}$ \\
\hline$v_{s}$ & $138 \mathrm{~m} / \mathrm{s}$ & $155 \mathrm{~m} / \mathrm{s}$ & $137 \mathrm{~m} / \mathrm{s}$ & $120 \mathrm{~m} / \mathrm{s}$ \\
\hline
\end{tabular}



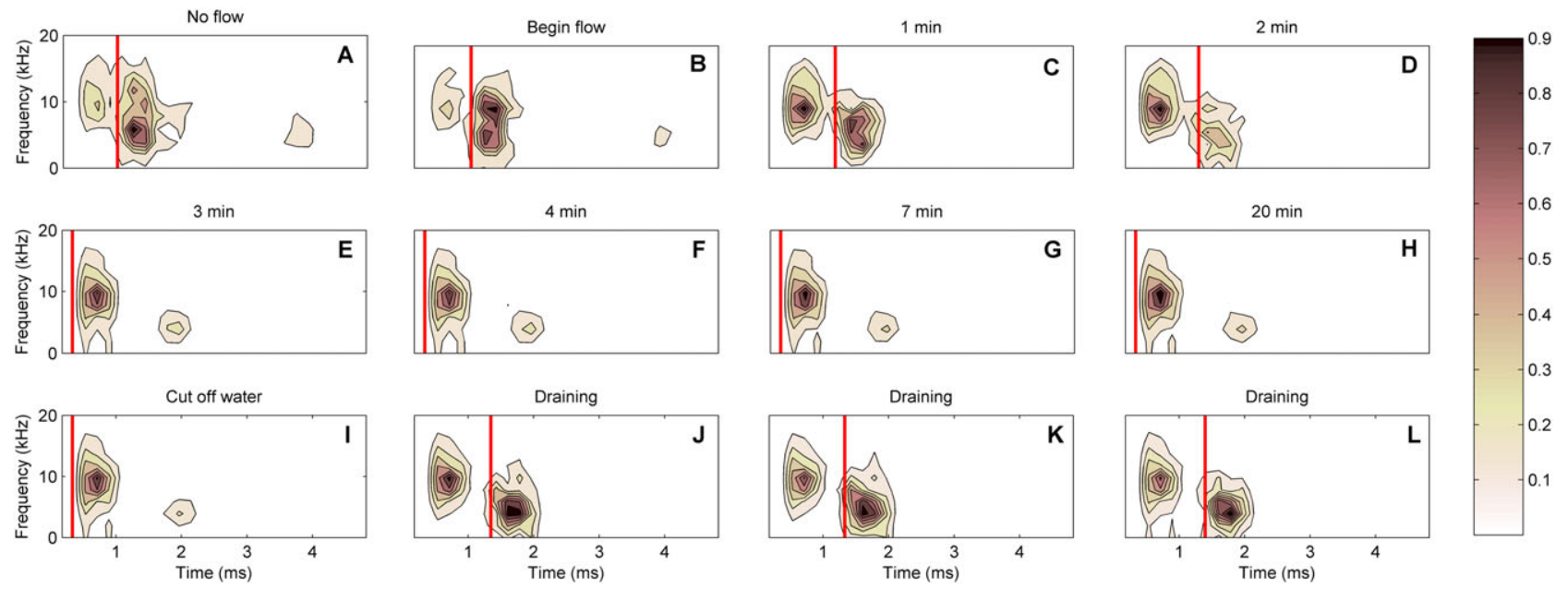

Figure 9 Relative power spectral density response for the single dynamic wetting/drying time-histories shown in Fig. 6. Panels A-D and J-L have an identifiable s-wave. Panels E-I do not have identifiable s-waves.
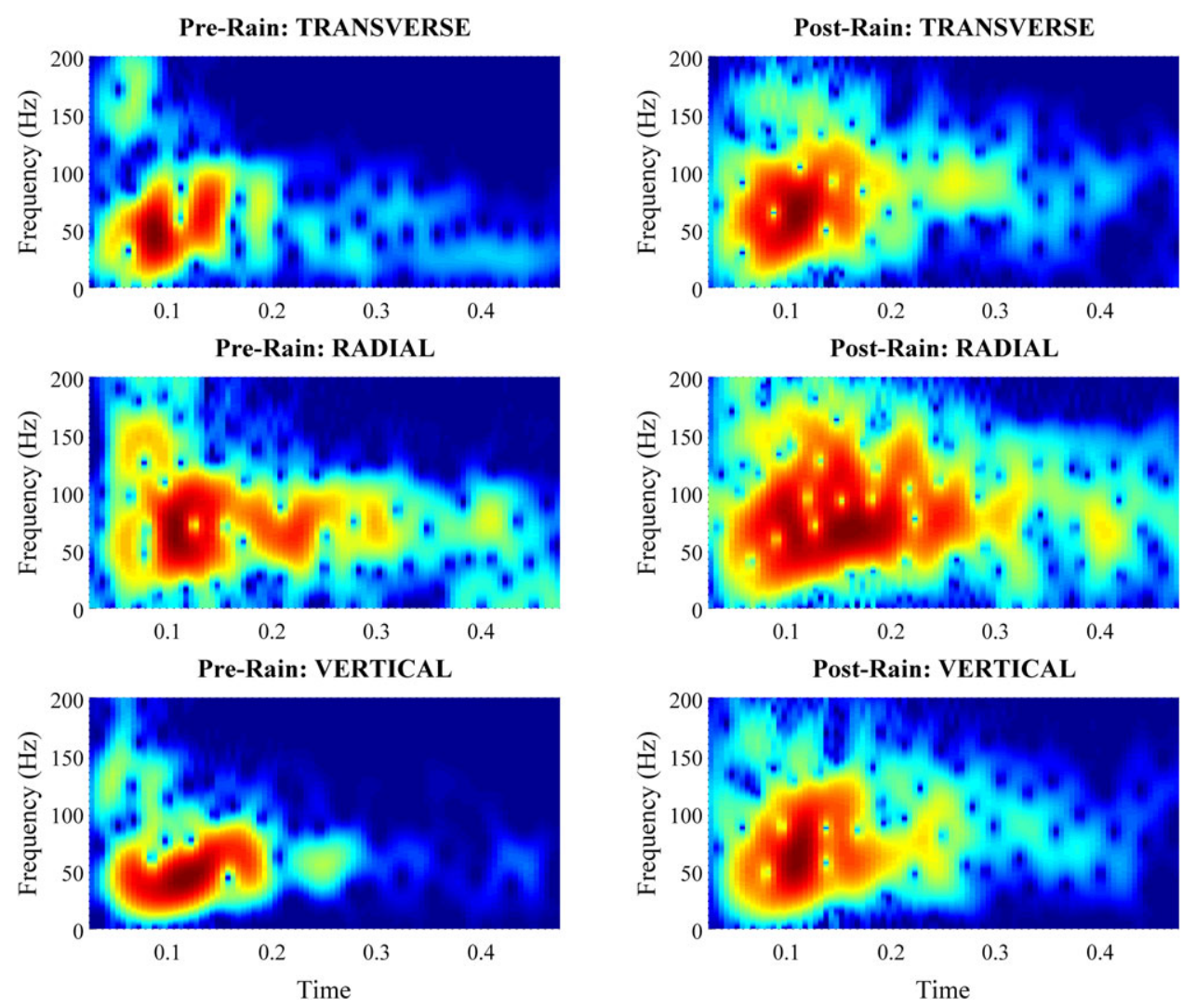

Figure 10 Relative power spectral density of the field geophone response pre- and post-rain event (from Taylor et al. 2014).

\subsection{Comparison of the UNIT data to field observations}

Taylor et al. (2014) noted significant variability within the preand post-rain waveforms generated from the same source. Using the radial axis, the ultrasonic near-surface inundation test- ing (UNIT) data was compared to the field geophone response to see if the UNIT accurately reflected the filed phenomenology. The radial axis was used as it is the weakest principle axis within the soil which would be the most sensitive to structural changes within the soil fabric. An initial comparison of the $v_{s}$ 
and $v_{p}$ pre-rain velocities were made with the residual region, $S<13 \%$, within the UNIT, Table 2 . The pre-rain and UNIT $v_{p}$ and $v_{s}$ measurements were in good agreement with the dry field condition from Taylor et al. (2014). Due to the operational nature of the data collection by Taylor et al. (2014), no discrete field saturation or soil sample was obtained. From the $v_{p}$ field data, $333 \mathrm{~m} / \mathrm{s}$, a correlation was made via the UNIT $v_{p}$ data, equation (4), to determine the approximate degree of saturation post-rain of approximately $25 \%$. The resulting UNIT and field $v_{s}$ differ by $26 \mathrm{~m} / \mathrm{s}$, due to the use of a proxy physical field sample in conjunction with a distribution of possible $v_{s}$ values, the phenomenology recreation was further correlated via amplification of the received signal. Taylor et al. (2014) observed a 4.6-fold increase in the maximum absolute radial post-rain velocity. Comparing the average UNIT bender element received signal voltage output for all $v_{p}$ in the residual region (less than $15 \%$ gravimetric saturation) and the average voltage for gravimetric saturations between $21 \%$ and $28 \%$, there was an average signal amplification of 1.6 -fold similar to the $v_{p}$ amplitude increase from Taylor et al. (2014).

Taylor et al. (2014) also noted that there was a significant shift in dominant frequency between pre- and post-rain events. While the UNIT and field sources vary significantly in frequency content, the relative power spectral densities were compared for similarities in shape with increased moisture. Figure 9 shows that within the UNIT a similar decreasing shift in dominant frequency occurred between the residual (Panel A) and draining conditions (Panels J-L) similar to the frequency decrease observed in the radial geophones from Taylor et al. (2014), Fig. 10. It should be noted that as water is flowing into the sample (Panels B-H), the dominant frequency increases significantly compared to the residual condition (Panel A).

\section{CONCLUSIONS}

Although it will never be ideal to install seismic sensors in near-surface soil, less than $1 \mathrm{~m}$ of overburden, the operational necessity of doing so for rapidly deployable, semi-permanent seismic arrays dictates that this can no longer be a neglected field of research in order to ensure accurate detection, classification and localization of seismic events utilizing the meteorologically sensitive $\mathrm{p}$-wave and shear wave portions of the wavefield. Field data from Taylor et al. (2014) illustrated a significant signal amplitude increase, change in frequency content with no change in signal duration before and after 36 hours of steady precipitation. Laboratory replication of these phenomena has never before been demonstrated due to the lack of appropriate equipment.

A new Ultrasonic Near-surface Inundation Testing (UNIT) device is presented as a means to study the effects of moisture and inundation within the near-surface environment where confining pressures are negligible and wave propagation is greatly influenced by the soil structure and saturation. The data presented here adequately replicates field observations of shallow-buried geophysical sensors during meteorological events and identifies important wave behavioural characteristics for future flow experimentation, sensor processing and system performance optimization. Additionally, the development of new $v_{p}$-saturation and $v_{s}$-saturation relationships as a function of the matric suction of the soil indicates that the UNIT device can be used to investigate seismic propagation under active inundation conditions and for the derivation of appropriate moduli.

\section{ACKNOWLEDGEMENTS}

The authors would like to acknowledge and thank the anonymous reviewers for their critical comments. The research was funded through the Assistant Secretary of the Army, Acquisition, Logistics and Technology (ASAALT) Project 61102/T22/01. Permission to publish was granted by Director, Geotechnical and Structures Laboratory, U.S. Army Engineer Research and Development Center; distribution is unlimited.

\section{REFERENCES}

Arulnathan R., Boulanger R. and Riemer M. 1998. Analysis of bender element tests. Geotechnical Testing Journal 21, 120-131.

Bachrach R. and Nur A. 1998a. High-resolution shallow-seismic experiments in sand, part 1: water table, fluid flow, and saturation. Geophysics 63, 1225-1233.

Bachrach R. and Nur A. 1998b. High-resolution shallow-seismic experiments in sand, part 1: velocities in shallow unconsolidated sand. Geophysics 63, 1234-1240.

Bachrach R., Dvorkin J. and Nur A. 2000. Seismic velocities and Poisson's ratio of shallow unconsolidated sands. Geophysics 65, 559-564.

Barriere J., Bordes C., Brito D., Senechal P. and Perroud H. 2012. Laboratory monitoring of $\mathrm{P}$ waves in partially saturated sand. Geophysical Journal International 191, 1152-1170.

Bates C.R. 1989. Dynamic soil property measurements during triaxial testing. Geotechnique 39, 721-726.

Bergamo P., Dashwood B., Uhlemann S., Swift R., Chambers J., Gunn D., et al. 2016a. Time-lapse monitoring of climate effects on earthworks using surface waves. Geophysics 81, EN1-EN15. 
Bergamo P., Dashwood B., Uhlemann S., Swift R., Chambers J., Gunn D., et al. 2016b. Time-lapse monitoring of fluid-induced geophysical property variations within an unstable earthwork using P-wave refraction. Geophysics 81, EN17-EN27.

Biot M. 1956. Theory of elastic waves in a fluid-saturated porous solid. 1. Low frequency range. The Journal of the Acoustical Society of America 28, 168-178.

Bishop A. and Blight G. 1963. Some aspects of effective stress in saturated and partly saturated soils. Geotechnique 13, 177196.

Bonner J., Waxler R., Gitterman Y. and Hofstetter R. 2013. Seismoacoustic energy partitioning at near-source and local distances from the 2011 sayarim explosions in the Negev desert, Israel. Bulletin of the Seismological Society of America 103, 741-758.

Brignoli E.G.M., Gotti M. and Stokoe K.H., II 1996. Measurement of shear waves in laboratory specimens by means of piezoelectric transducers. Geotechnical Testing Journal 19, 384-397.

Carlson A.B. 1986. Communication Systems-An Introduction to Signals and Noise in Electrical Communication. McGraw-Hill, New York.

Chapman M. 2013. On the rupture process of the 23 august 2011 Virginia earthquake. Bulletin of the Seismological Society of America 103, 613-628.

Cho G. and Santamarina J. 2001. Unsaturated particulate materials particle-level studies. Journal of Geotechnical and Geoenvironment Engineering 127, 84-96.

Cho G., Dodds J. and Santamarina J.C. 2006. Particle shape on packing density, stiffness, and strength: natural and crushed sands. Journal of Geotechnical and Geoenvironment Engineering 132, 591602.

Crane J., Lorenzo J. and Harris J. 2013. A new electrical and mechanical detonatable shear wave source for near surface $(0-30 \mathrm{~m})$ seismic acquisition. Journal of Applied Geophysics 91, 1-8.

Fratta D., Alshibli K., Tanner W. and Roussel L. 2005. Combined TRD and P-wave velocity measurements for the determination of in situ soil density - experimental study. Geotechnical Testing Journal 28, 553-563.

Fredlund D. 2002. Use of the soil-water characteristic curve in the implementation of unsaturated soil mechanics. Proceedings of the Third International Conference on Unsaturated Soils, Recife, Brazil, March 2002.

Fredlund D., Rahardjo H. and Fredlund M. 2012. Unsaturated Soil Mechanics in Engineering Practice. John Wiley \& Sons.

Gassmann F. 1951. Uber die elastizitat poroser medien. Veirteljahrsschrift der Naturforshenden Gesellshaft in Zurich 96, 1-23.

Gu X., Yang J. and Huang M. 2013. Laboratory measurements of small strain properties of dry sands by bender element. Soils and Foundations 53, 735-745.

Han Z. and Vanapalli S. 2016. Stiffness and shear strength of unsaturated soils in relation to soil-water characteristic curve. Geotechnique 66, 627-647.

Hasbrouck W. 1991. Four shallow-depth, shear-wave feasibility studies. Geophysics 56, 1875-1885.

Hassanizadeh S., Celia M. and Dahle H. 2002. Dynamic effect in the capillary pressure-saturation relationship and its impacts on unsaturated flow. Vadose Zone Journal 1, 38-57.
Houston S., Houston W. and Spadola D. 1988. Prediction of field collapse of soils due to wetting. Journal of Geotechnical and Geoenvironment Engineering 114, 40-58.

Ishihara K., Huang Y. and Tsuchiya H. 1998. Liquefaction resistance of nearly saturated sand as correlated with longitudinal wave velocity. In: Poromechanics: A tribute to Maurice A. Biot, (eds J. Thimus, Y. Abousleiman, A. Cheng, O. Coussy and E. Detournay), pp. 583-586. Balkema, Rotter- dam, The Netherlands.

Jolly R. 1956. Investigation of shear waves. Geophysics 21, $905-$ 1110.

Koper K., Wallace T. and Aster R. 2003. Seismic recordings of the Carlsbad, New Mexico, pipeline explosion of 19 August 2000. Bulletin of the Seismological Society of America 93, 1427-1432.

Lee J.-S. and Santamarina J. 2005. Bender elements: Performance and signal interpretation. Journal of Geotechnical and Geoenvironment Engineering 131, 1063-1070.

Leong E., Yeo S. and Rahardjo H. 2005. Measuring shear wave velocity using bender elements. Geotechnical Testing Journal 28, 488498.

Lu N. and Likos W. 2006. Suction stress characteristic curve for unsaturated soil. Journal of Geotechnical and Geoenvironment Engineering 132, 131-142.

Lu N., Godt J. and Wu D. 2010. A closed-form equation for effective stress in unsaturated soil. Water Resources Research 46, W05515.

Lu Z. and Sabatier J. 2009. Effects of soil water potential and moisture content on sound speed. Soil Science Society of America Journal 73, 1614-1625.

Malaya C. and Sreedeep S. 2012. Critical review on the parameters influencing soil-water characteristic curve. Journal of Irrigation and Drainage Engineering 138, 55-62.

Miller R., Pullan S., Waldner J. and Haeni F. 1986. Field comparison of shallow seismic sources. Geophysics 51, 2067-2092.

Miller R., Pullan S., Steeples D. and Hunter J. 1992. Field comparison of shallow seismic sources near Chino, California. Geophysics 57, 693-709.

Muraleetharan K., Hoyos L. and Ge L. 2016. Special issue on experimental and computational geomechanics for unsaturated soils. International Journal of Geomechanics 16, D2016001.

Naesgaard E., Byrne P. and Wijewckreme D. 2007. Is P-wave velocity an indicator of saturation in sand with viscous pore fluid? International Journal of Geomechanics 7, 437-443.

Oelze M., O’Brien Jr., W. and Darmody R. 2002. Measurement of attenuation and speed of sound in soils. Soil Science Society of America Journal 66, 788-796.

Pennington D.S., Nash D.F.T. and Lings M.L. 2001. Horizontally mounted bender elements for measuring anistropic shear moduli in triaxial clay specimens. Geotechnical Testing Journal 24, 133-144.

Press W., Flannery B., Teukolsky S. and Vetterling W. 1986. Numerical Recipes. Cambridge University Press.

Santamarina J. 2001. Soil behavior at the microscale: particle forces. Proceedings of a Symposium on Soil Behavior and Soft Ground Construction in honor of Charles C. Ladd, Boston, MA, October 2001 pp. 1-32. MIT.

Shen J., Crane J., Lorenzo J. and White C. 2016. Seismic velocity prediction in shallow $(30 \mathrm{~m})$ partially saturated sand. Journal of Environmental and Engineering Geophysics 21, 67-78. 
Shirley D.J. 1978. An improved shear wave transducer. Journal of Acoustic Society of America 63, 1643-1645.

Smart E. and Flinn E. 1971. Fast frequency-wavenumber analysis and fisher signal detection in real-time infrasonic array data processing. Geophysical Journal International 26, 279-284.

Song A.J., West B.A., Taylor O.-D., O’Connor D., Parno M., Hodgdon T., et al. 2017. "Munition penetration-depth prediction" ERDC/CRREL TR-17-12. U.S. Army Engineer Research and Deve lopment Center, Hanover, NH.

Stump B., Pearson D. and Reinke R. 1999. Source comparisons between nuclear and chemical explosions detonated at rainier mesa, Nevada test site. Bulletin of the Seismological Society of America 89, 409-422.

Sture S., Costes N., Batiste S., Lankton M., Al Shibli K., Jeremic B., et al. 1998. Mechanics of granular materials at low effective stresses. Journal of Aerospace Engineering 11, 67-72.

Swarztrauber P. 1982. Vectorizing the FFT's in Parallel Computations. Academic Press.

Takahashi H., Kitazume M., Ishibasi S. and Yamawaki S. 2006. Evaluating the saturation of model ground by P-wave velocity and modeling of models for a liquefaction study. International Journal of Physical Modelling in Geotechnics 1, 13-15.

Tamura S., Tokimatsu K., Abe A. and Sato M. 2002. Effects of air bubbles on B-value and P-wave velocity of a partly saturated sand. Soils Found 42, 121-129.

Taylor O.-D. and Martin K. 2017. Ultrasonic near-surface inundation testing device. U.S. Patent 9,606,087-B1, issued March 28, 2017.

Taylor O.-D. and Winters K. 2017. Resonant column behavior of unsaturated near-surface sands. Proceedings of the Second PAN American Conference on Unsaturated Soil Mechanics, Dallas, TX, November 2017.

Taylor O.-D.S., McKenna M., Kelley J., Berry T., Quinn B. and McKenna J. 2014. Partially saturated soil causing variability in near surface seismic signals: a case history. Near Surface Geophysics 12, $467-480$.
Taylor O.S., Berry W., Winters K., Rowland W., Antwine M. and Cunningham A. 2017. Protocol for cohesionless sample preparation for physical experimentation. Geotechnical Testing Journal 40, 284-301.

Taylor O.-D., Winters K., Berry W., Walshire L. and Kinnebrew P. 2019. Near-surface soils: self-supported unconfined drained sand specimens. Canadian Geotechnical Journal 56, 307-319.

Tsoflias G., Steeples D., Czarnecki G., Sloan S. and Eslick R. 2006. Automatic deployment of a 2-D geophone array for efficient ultrashallow seismic imaging. Geophysical Research Letter 33, L09301.

Tsukamoto Y., Ishihara K., Nakazawa H., Kamada K. and Huang H. 2002. Resistance of partly saturated sand to liquefaction with reference to longitudinal and shear wave velocities. Soils Found $\mathbf{4 2}$, 93-104.

Vanapalli S.K., Fredlund D.G., Pufahl D.E. and Clifton A.W. 1996. Model for the prediction of shear strength with respect to soil suction. Canadian Geotechnical Journal 33(3), 379-392. https://doi.org/10.1139/t96-060.

van Genuchten M.T. 1980. A closed form equation predicting the hydraulic conductivity of unsaturated soils. Soil Science Society of America Journal 44, 892-898.

Viana da Fonseca A., Ferreira C. and Fahey M. 2009. A framework interpreting bender element tests, combining time-domain and frequency domain methods. Geotechnical Testing Journal 32, $1-17$.

Walshire L.A., Taylor O.-D.S. and Berry W.W. 2017. “Testing Method and Fabric Effects on the SWCC of a Poorly Graded Sand." Proceedings of the Second PAN American Conference on Unsaturated Soil Mechanics, Dallas, TX, 2017.

Yang J. 2002. Liquefaction resistance of sand in relation to P-wave velocity. Geotechnique 52, 295-298.

Yordkayhun S., Ivanova A., Giese R., Juhlin C., Cosma C. 2009. Comparison of surface seismic sources at the CO2SINK site, Ketzin, Germany. Geophysical Prospecting 57, 125-139. 


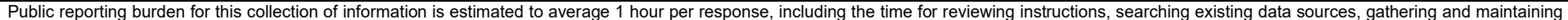

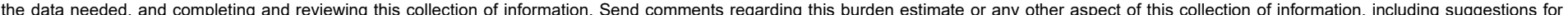

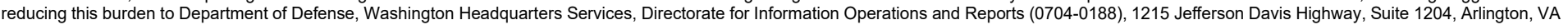

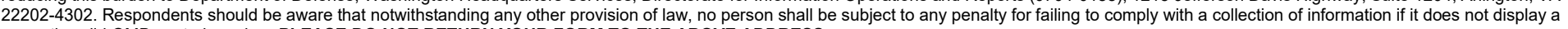
currently valid OMB control number. PLEASE DO NOT RETURN YOUR FORM TO THE ABOVE ADDRESS.
1. REPORT DATE (DD-MM-YYYY)
August 2021

\section{TITLE AND SUBTITLE}

The Behaviour of Near-Surface Soils Through Ultrasonic Near-Surface Inundation Testing

\section{AUTHOR(S)}

Oliver-Denzil S. Taylor, Amy L. Cunningham, Robert E. Walker, Mihan H. McKenna, Kathryn E. Martin, and Pamela G. Kinnebrew

\section{PERFORMING ORGANIZATION NAME(S) AND ADDRESS(ES)}

Geotechnical and Structures Laboratory

U.S. Army Engineer Research and Development Center

3909 Halls Ferry Road

Vicksburg, MS 39180

\section{SPONSORING / MONITORING AGENCY NAME(S) AND ADDRESS(ES)}

Assistant Secretary of the Army, Acquisition, Logistics and Technology (ASAALT)

Washington, DC 20314

\section{DATES COVERED (From - To)}

5a. CONTRACT NUMBER

5b. GRANT NUMBER

5c. PROGRAM ELEMENT NUMBER

5d. PROJECT NUMBER

5e. TASK NUMBER

\section{5f. WORK UNIT NUMBER}

8. PERFORMING ORGANIZATION REPORT NUMBER

ERDC/GSL MP-21-4

10. SPONSOR/MONITOR'S ACRONYM(S)

11. SPONSOR/MONITOR'S REPORT NUMBER(S)

\section{DISTRIBUTION / AVAILABILITY STATEMENT}

Approved for public release; distribution is unlimited.

\section{SUPPLEMENTARY NOTES}

This article was originally published online in Near Surface Geophysics on 24 April 2019.

This research was funded through the Assistant Secretary of the Army, Acquisition, Logistics and Technology (ASAALT)

Project 61102/T22/01.

\section{ABSTRACT}

Seismometers installed within the upper metre of the subsurface can experience significant variability in signal propagation and attenuation properties of observed arrivals due to meteorological events. For example, during rain events, both the time and frequency representations of observed seismic waveforms can be significantly altered, complicating potential automatic signal processing efforts. Historically, a lack of laboratory equipment to explicitly investigate the effects of active inundation on seismic wave properties in the near surface prevented recreation of the observed phenomena in a controlled environment. Presented herein is a new flow chamber designed specifically for near-surface seismic wave/fluid flow interaction phenomenology research, the ultrasonic near-surface inundation testing device and new $v p$-saturation and $v s$-saturation relationships due to the effects of matric suction on the soil fabric.

\section{SUBJECT TERMS}

Near surface, Seismic, S-wave, Soil, Velocity

\section{SECURITY CLASSIFICATION OF:}

\section{a. REPORT}

Unclassified

\section{b. ABSTRACT}

Unclassified c. THIS PAGE

Unclassified
17. LIMITATION OF ABSTRACT

UU 18. NUMBER
OF PAGES

19 19a. NAME OF RESPONSIBLE PERSON

19b. TELEPHONE NUMBER (include area code) 